\title{
Recurrent hypoglycaemia and a slowly rising hemidiaphragm: A
} case report.

\author{
Vincent Simpson ${ }^{1}$ and Andrew McGovern ${ }^{1}$ \\ ${ }^{1}$ Royal Devon and Exeter NHS Foundation Trust
}

April 7, 2021

\begin{abstract}
A 92-year-old man presented to the hospital with recurrent hypoglycemia with a chronically raised right hemidiaphragm. A CT thorax-abdomen-pelvis showed a large abdominal mass. A 'big' IGF-2 secreting non-islet cell tumour was suspected and confirmed. The patient was treated with low dose prednisolone.
\end{abstract}

\section{Recurrent hypoglycaemia and a slowly rising hemidiaphragm: A case report}

A 92-year-old man presented to the hospital with a fall. On arrival of the ambulance crew at his home he was found to be hypoglycaemic $(1.8 \mathrm{mmol} / \mathrm{L}$; reference range $4 \cdot 0-6.0 \mathrm{mmol} / \mathrm{L})$ and was treated with intravenous glucose. He reported several falls over the preceding few weeks, usually occurring in the morning. He had no other symptoms and no preceding history of increased hunger or weight change. His past medical history included chronic obstructive pulmonary disease, ischaemic heart disease, and chronic lymphocytic leukaemia but not diabetes. He was not prescribed any glucose-lowering medication. His complete blood count demonstrated a mild chronic normocytic anaemia (haemoglobin $114 \mathrm{~g} / \mathrm{L} ; 130-180 \mathrm{~g} / \mathrm{L}$ ) but was otherwise unremarkable. Serum electrolytes, liver function tests, thyroid function tests, and C-reactive protein were all normal. His chest x-ray showed a chronically raised right hemidiaphragm. He was kept in overnight for observation and glucose monitoring. At 05:00 he had a further hypoglycaemic episode (venous glucose 1.9 $\mathrm{mmol} / \mathrm{L})$. The simultaneous measurement showed an appropriately low c-peptide $(<94 \mathrm{pmol} / \mathrm{L} ; 370-1470$ $\mathrm{pmol} / \mathrm{L})$ and low insulin level $(<2 \cdot 8 \mathrm{pmol} / \mathrm{L} ; 17 \cdot 8-173 \cdot 0 \mathrm{pmol} / \mathrm{L})$. A short Synacthen test excluded adrenal insufficiency. An echocardiogram done for a new ejection systolic murmur showed moderate to severe aortic stenosis but also showed right atrial compression. We suspected a 'big' Insulin-like growth factor-2 (IGF2) producing tumour and requested IGF levels and a CT thorax-abdomen-pelvis. Pending test results, he was started on a modest dose of hydrocortisone (10mg at night) and an evening snack. His IGF-1 was at the lower end of the reference range $(8.2 \mathrm{nmol} / \mathrm{L} ; 4 \cdot 6-23.4 \mathrm{nmol} / \mathrm{L})$, with an increased IGF-2:IGF-1 ratio $(17 \cdot 2 ;<10$ [IGF-2 $140 \cdot 7 \mathrm{nmol} / \mathrm{L}])$ in keeping with non-islet cell tumour hypoglycaemia. His CT showed a large heterogeneous mass $(18.3 \times 15.7 \mathrm{~cm})$ with central calcification above the right hemidiaphragm with associated partial superior vena cava obstruction and liver displacement (figure 1 ). Retrospectively reviewing his chest $\mathrm{x}$-rays, the mass was evident as a steadily rising right hemidiaphragm over 10 years (figure 2 ). He experienced no further hypoglycaemia on the low dose of prednisolone and therefore this was not increased. Due to his age and comorbidities, this conservative treatment was considered the optimal treatment option. Subsequent home measurement of his morning capillary blood glucose levels suggested good prevention of hypoglycaemic events (ranging $6 \cdot 1-7 \cdot 1 \mathrm{mmol} / \mathrm{L} ; 4 \cdot 0-6 \cdot 0 \mathrm{mmol} / \mathrm{L}$ ).

Non-islet cell tumour hypoglycaemia is a rare cause of hypoglycaemia and caused by IGF-2 secretion from large tumours usually arising from mesenchymal origin (41\%), though it can arise from any cell line.1 These tumours produce high molecular weight "big" IGF-2 which acts similarly to insulin, inhibiting glucose release 
from the liver and increasing skeletal muscle uptake.2 In turn this suppresses growth hormone, insulin, IGF-1 and glucagon

release thereby increasing the risk of hypoglycaemia. Treatment is either with resection of the tumour or, where this is not possible, high dose steroids (e.g. 30-60mg prednisolone) with either somatostatins or growth hormone. 1,2

This case demonstrates the importance of reviewing serial x-rays for more insidious slow-growing tumours. Successful suppression of hypoglycaemic events in non-islet cell tumour hypoglycaemia can be achieved with relatively low doses of prednisolone (here prednisolone $10 \mathrm{mg}$ orally taken at night) although other reports suggest higher doses are usually needed.1,2

\section{Contributors}

VS and AMcG were involved in the clinical care of the patient and the preparation of the manuscript. Both authors read and approved the final submitted version. Written informed consent was obtained from the patient's next of kin as the patient had unfortunately passed away from unrelated pneumonia at the time of writing.

\section{Declaration of interests}

We declare no competing interests.

\section{References}

1. De Groot, J. W. B., Rikhof, B., Van Doorn, J., Bilo, H. J. G., Alleman, M. A., Honkoop, A. H., \& Van Der Graaf, W. T. A. (2007). Non-islet cell tumour-induced hypoglycaemia: A review of the literature including two new cases. Endocrine-Related Cancer, 14(4), 979-993. https://doi.org/10.1677/ERC-07-0161 2. Timothy W. Bodnar, Maria J. Acevedo, and Massimo Pietropaolo (2013). Management of Non-Islet-Cell Tumor Hypoglycemia: A Clinical Review.JCEM, 99(3), 713-722. 


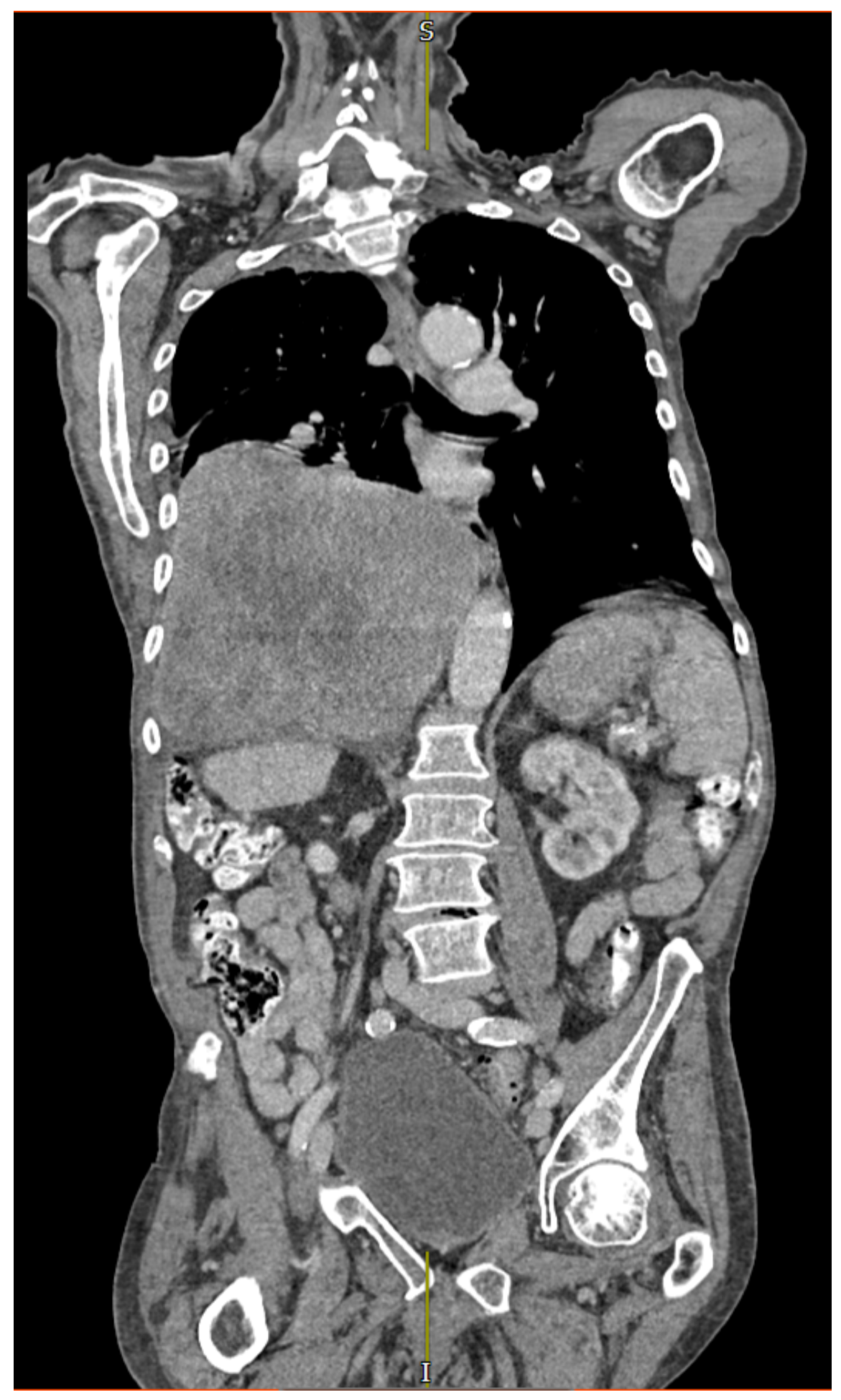



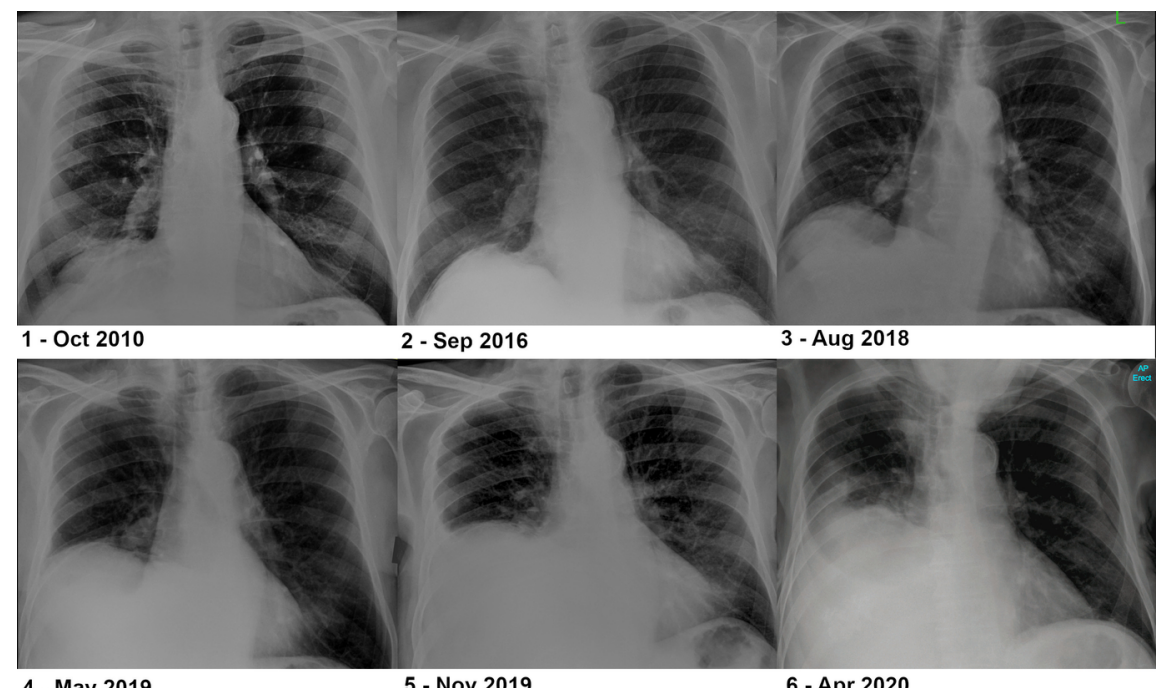

4 - May 2019

5 - Nov 2019

6 - Apr 2020

\section{Hosted file}

Case_Report_CXR_Date_Slow.gif available at https://authorea.com/users/406188/articles/516944recurrent-hypoglycaemia-and-a-slowly-rising-hemidiaphragm-a-case-report 